\title{
A large sample study on the influence of the multisensory environment on the wine drinking experience
}

\author{
Charles Spence $^{1 *}$, Carlos Velasco ${ }^{1}$ and Klemens Knoeferle ${ }^{2}$
}

\begin{abstract}
Background: We report on what may well be the world's largest multisensory tasting experiment. Over a period of 4 days in May 2014, almost 3,000 people sampled a glass of red wine in a room in which the colour of the lighting and/or the music was changed repeatedly. The participants rated the wine, presented in a black tasting glass, on taste, intensity and liking scales while standing in each of four different environments over a period of 7 to 8 minutes. During the first 2 days (Experiment 1), the participants rated the wine while exposed to white lighting, red lighting, green lighting with music designed to enhance sourness and finally under red lighting paired with music associated with sweetness. During the latter 2 days of the event (Experiment 2), the same wine was rated under white lighting, green lighting, red lighting with sweet music and finally green lighting with sour music.

Results: In Experiment 1, the wine was perceived as fresher and less intense under green lighting and sour music, as compared to any of the other three environments. On average, the participants liked the wine most under red lighting while listening to sweet music. A similar pattern of results was reported in Experiment 2.

Conclusions: These results demonstrate that the environment can exert a significant influence on the perception of wine (at least in a random sample of social drinkers). We outline a number of possible explanations for how the sensory properties of the environment might influence the perception of wine. Finally, we consider some of the implications of these results for the wine drinking experience.
\end{abstract}

Keywords: Wine, Colour, Music, Environment, Atmospherics, Multisensory, Tasting

\section{Background}

An extensive literature demonstrates that changing the colour of foods or beverages often modulates their perceived taste and/or flavour among both regular consumers and experts alike (for example, [1-4]). Changing the colour of the packaging, or receptacle, in which a product is presented and/or consumed can influence people's perception of the contents as well $[5,6]$. However, as yet, far less research has looked at the question of whether changing the colour of the environment in which people eat or drink can also affect their tasting/ consumption experiences. To date, a few studies have varied the overall level of ambient illumination in order to mask the colour of the food (for example, [7]).

\footnotetext{
* Correspondence: charles.spence@psy.ox.ac.uk

${ }^{1}$ Crossmodal Research Laboratory, Department of Experimental Psychology,

University of Oxford, 9 South Parks Road, Oxford OX1 3UD, UK

Full list of author information is available at the end of the article
}

Meanwhile, Gal et al. [8] varied the brightness of the lighting and demonstrated its influence on the consumption of a hot beverage. Most recently, Xu and Labroo [9] reported that the participants in a laboratory study chose a spicier sauce (from a range of 16 possible sauces) for chicken wings under brighter (as compared to dimmer) ambient illumination. There have also been anecdotal reports of others changing the colour of the environment in order to induce a particular mood in diners [10].

\section{Environmental colour and taste/flavour perception}

A small number of well-controlled studies have specifically examined the effect of varying the hue of the ambient lighting on people's rating of drinks sampled from black tasting glasses [11-13] ${ }^{a}$. In one such study, Oberfeld et al. [11] demonstrated a significant effect of environmental lighting on people's rating of white wine. One experiment was conducted in a winery on the Rhine, while two 
follow-up studies were conducted back in the psychology lab. Changing the colour of the lighting (white, red, green or blue) exerted a significant effect on people's responses to the wine in each and every experiment. That said, nature of that change was not altogether consistent from one experiment to the next.

In Oberfeld et al. [11] first experiment (conducted in the winery), people rated a Riesling white wine as significantly more pleasant and said that they would pay significantly more for a bottle of the wine under the red lighting (than under any of the other three lighting colours). In a second study, this time conducted in the psychology laboratory, the same red lighting resulted in the white wine being rated as less spicy (as compared to when the same wine was rated while under blue or green lighting) and less fruity (as compared to green and white lighting). Interestingly, no significant effect on the perceived value of the wine was obtained on this occasion ${ }^{\mathrm{b}}$. In a third experiment, the wine was rated as tasting fruitier under the red lighting as compared to when it was evaluated under blue lighting. The wine also tasted sweeter under the red lighting as compared to blue or white lighting $[13,14]$. While these results are undoubtedly intriguing, it is worth noting that earlier studies in this area (for example, [12]) found no such effect of changes in the ambient lighting on people's perception of wine. Given the mixed results that have been published in the literature $[14,15]$, it seemed sensible to try and resolve once and for all the question of whether changing the hue of the ambient lighting would change the way in which social drinkers rate wine.

The ambient lighting colours used in the present study were selected on the basis of Oberfeld et al. [11], as well as on the basis of a pre-test of various light colours prior to the main data collection event (reported below). Given the within-participants nature of this public event, and the fact that the whole experience was designed to last no more than 7 or 8 minutes, we were unable to test a wide range of ambient colours. Red and green seemed appropriate given the natural associations that exist between green and unripe (that is, sour and possibly bitter) fruits and red and ripe (that is, sweet) fruits [16-21].

\section{Background music and taste/flavour perception}

Beyond any impact of changing the hue of the ambient lighting (white, red or green) on people's perception of a glass of (red) wine, as tasted from a black tasting glass, we were also interested in any additional effect that varying the musical environment might have on the participants' wine tasting experience. A spate of recent studies have demonstrated that simply by changing the music playing in the background one can effectively change how people rate the taste of a drink or food, and/or how much they enjoy the overall experience (see [22-27]).
Extending this line of research, we wanted to know whether playing short musical selections during the wine tasting would have any additional influence on participants' judgements over-and-above that elicited by changing the lighting. To this end, we complemented some of the lighting conditions with recently-generated (and tested) musical selections that have been shown to be associated in the general population with sour or sweet tastes (Knoeferle KM, Woods A, Käppler F, Spence C: That sounds sweet: Using crossmodal correspondences to communicate gustatory attributes. Psychol Market, submitted).

Note that, to date, the majority of studies have either looked only at the effects of changing the ambient lighting or only at the presentation of various background music/ soundscapes, but never at the two together. Two possible kinds of result might be predicted given the literature on multisensory perception [28,29]: on the one hand, an additive or possibly even superadditive effect (that is, an effect that is bigger than one would expect simply by combining the effect of each cue when presented individually) of combining congruent visual and auditory environmental cues might be obtained [30,31]. On the other hand, however, one might also legitimately expect to find that vision was dominant, given our status as essentially visually-dominant creatures (for example, [32,33]), and hence the addition of background sound might not have any effect over and above that attributable to the lighting.

\section{Study objectives}

In the present study, we followed up on Oberfeld et al.'s [11] intriguing findings with a much larger sample. More specifically, we collected data from almost 3,000 participants as compared to 200 in the largest of Oberfeld et al. three experiment. The study, presented to members of the public as The Colour Lab, was conducted over a period of four successive days at the start of May 2014, in a central London location (under The Southbank Centre). We used a within-participants experimental design. The order in which the various environmental conditions were presented was different on the first 2 days, as compared to the last 2 days. For ease of analysis and presentation, though, the results collected on the first 2 days are treated as Experiment 1, while the results from the latter 2 days are treated as Experiment 2. In all regards except for the order and exact nature of the environmental conditions presented to the participants, these two studies were identical. Specifically, in Experiment 1 , the environmental conditions consisted of white lighting, red lighting, green lighting with sour music and red lighting with sweet music. In Experiment 2, the conditions consisted of white lighting, green lighting, red lighting with sweet music and green lighting with sour music. 


\section{Experiment 1}

\section{Methods and materials}

A total of 1,580 participants (871 women, 643 men and 66 who failed to specify) aged 18 to 90 years $(M=34.3$, $S D=11.9$ ) agreed to take part in The Colour Lab after the procedure had been explained to them. The experiment was reviewed and approved by the Central University Research Ethics Committee of the University of Oxford (reference number: MSD-IDREC-C1-2013-074), and complied with the Helsinki Declaration. Because the experiment was conducted through a public event, the participants did not sign a consent form; however, the purpose of the study and the experimental procedure were explained, and only the participants who agreed to participate were offered a place in the event. Any questions that the participants had were answered. The participants were informed that, by taking part of it, they were subject to having their photo taken and used after the event. Eight percent of the questionnaire ratings were not completed and therefore excluded from the subsequent data analysis.

The participants were initially briefly introduced to the art of wine tasting by a trained guide. They were also given a tasting strip sourced from Precision Laboratories in order to assess their sensitivity to PTC $[34,35]^{\mathrm{c}}$. This test is known to give rise to a wide range of different taste experiences: from no sensation at all through to one of extreme bitterness. The tasting strip was used in order to demonstrate the wide inter-individual variability that exists in the world of taste perception [36]. Those who found the tasting strip bitter were offered a glass of water to neutralise the taste prior to the wine tasting. The guide then spent 3 to 4 minutes introducing the wine and the experience that the participants were about to have.

Before entering the main experimental chamber, the participants were offered a glass (approximately $100 \mathrm{~mL}$ ) of Campo Viejo Reserva 2008 (Rioja) in a standard black ISO tasting glass. The wine itself is ruby red in colour, with bright and deep nuances. It features complex aromas with an excellent balance between the fruits (cherries, black plums, ripe blackberries) and the spices coming from the wood (clove, pepper, vanilla and coconut). The wine is aged in French and American oak and then in the bottle in the cellar. During this time, the wine's bouquet develops. The wine is smooth and balanced on the palate, has a full, elegant feel and a lingering finish.

The participants then entered a $14 \times 5 \mathrm{~m}$ rectangular room with white walls, floor and ceiling (Figure 1 ). The participants entered from one end of the room and exited from the other end.

Previous research has suggested that green tends to be associated with unripe (that is, sour and possibly bitter) fruits and red with ripe (that is, sweet) fruits (for example, [16-21]). Having said that, Experiments 1 and 2 included three lighting conditions: red light, green light

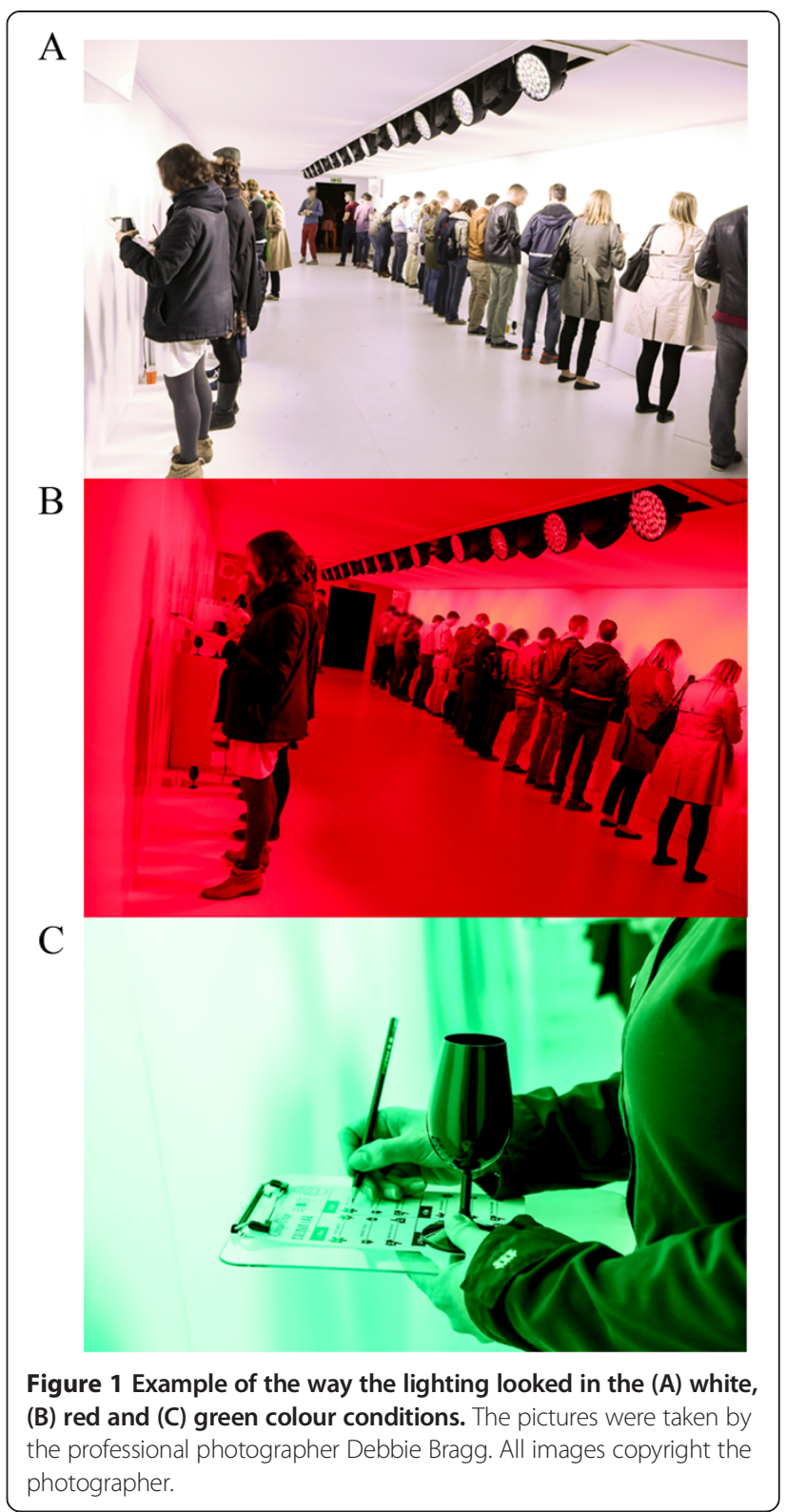

and white light. The first two were included assuming that these colours can presumably be associated to taste features such as sweet and sour, and the latter as a control.

The sounds used in the present study were taken from a recent study by (Knoeferle KM, Woods A, Käppler F, Spence C: That sounds sweet: Using crossmodal correspondences to communicate gustatory attributes. Psychol Market, submitted). On the basis of a series of laboratory studies conducted here at Oxford University, we (as well as several other research groups) have been working on trying and elucidating those musical features that match certain basic taste properties (see [37], for a 
review). Two of the soundtracks resulting from this work were then fed into the present study: the sweet soundtrack was legato, low in auditory roughness and sharpness, and highly consonant. In contrast, the sour soundtrack was staccato, high in roughness and sharpness, and moderately consonant. Both soundtracks used otherwise identical musical material, consisting of a combination of relatively high-pitched foreground and background elements. In the two Western samples $\left(N_{1}=61, N_{2}=309\right)$ reported in (Knoeferle KM, Woods A, Käppler F, Spence C: That sounds sweet: Using crossmodal correspondences to communicate gustatory attributes. Psychol Market, submitted), the recognition rates for the sweet music were $57.4 \%$ and $61.6 \%$, while recognition rates for the sour music were $34.4 \%$ and $33.6 \%$ (forced choice matchings of four pieces of music with four basic tastes - hence chance level performance = $25 \%)$. The interested reader can download these short pieces of music at https://soundcloud.com/crossmodal/ sets/tastemusic. The musical selections were played at a comfortable listening level from several loudspeakers mounted over the experimental space.

Given that we expected the participants to consist mainly of social drinkers, the decision was made to keep the questionnaire as simple and intuitive as possible - that is, we tried to avoid the use of any wine language that some of the participants might not readily understand (Figure 2). Specifically, three 7-point
Likert scales were included in the study: one for taste/ flavour anchored with 'fruity' and 'fresh', one for intensity anchored with 'low' and 'high', and one for liking anchored with 'not at all' to 'very much'. Our choice of the fresh/fruity scale was based on a discussion with one of the wine-makers for the Campo Viejo brand, and seemed to capture two distinct attributes of the wine. These descriptors were felt to be the ones that the random sample of participants who were going to take part in the study would be able to identify readily. The participants were taken through the experience in groups of approximately 30 by one of four trained guides.

\section{Results}

Following a mixed design, a repeated measures analysis of variance (RM-ANOVA) with environment as a withinparticipants factor (four levels: white lighting, red lighting, green lighting with sour music, and red lighting with sweet music) and gender as a between-participants factor ${ }^{\mathrm{d}}$, was conducted on each of the three different attributes. Whenever sphericity was violated, Greenhouse-Geisser corrected values are presented. All pairwise comparisons reported in the text have been Bonferroni-corrected.

\section{Taste (fresh vs. fruity)}

The analysis revealed a significant main effect of the environment on participants' taste ratings, $F(2.902$, $4146.784)=127.310, P<0.001, \eta^{2}$ partial $=0.082$ (Figure 3A)

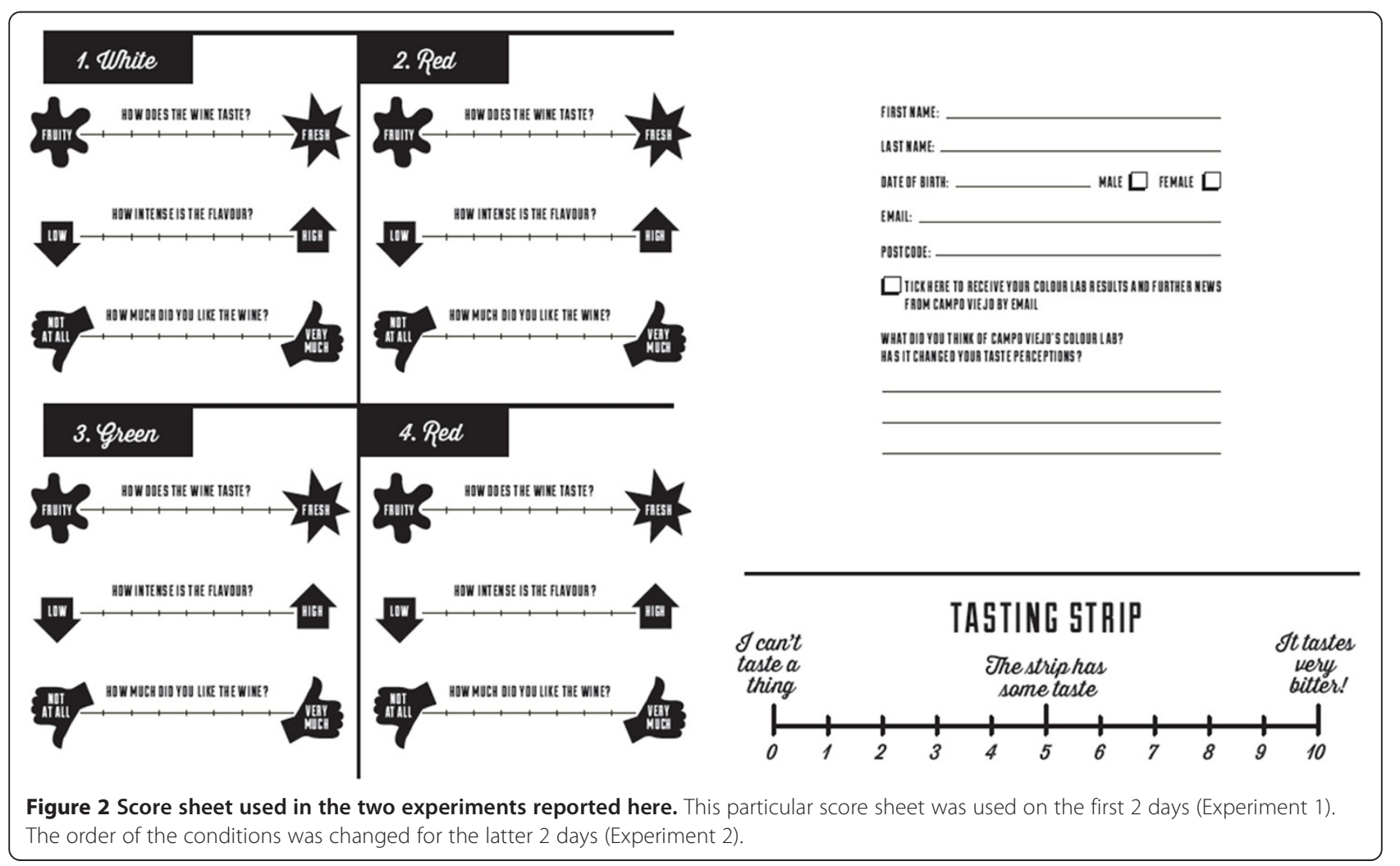


and a taste by gender interaction, $F(3,4287)=2.764, \quad P=$ $0.04, \eta_{\text {partial }}^{2}=0.002$. According to the results of pairwise comparisons, the participants rated the wine as tasting significantly fresher in the green lighting/sour music environment than in any one of the other three environments $(P$ $<0.001$ for all comparisons). The wine was also rated as tasting significantly fresher under white than under red lighting (no matter whether or not the putatively 'sweet' music was playing in the background; $P<0.001$ for both comparisons). In other words, compared to the white lighting baseline condition, green lighting brought out the wine's freshness, while the red lighting brought out the fruitier notes in the wine. Pairwise comparisons on the interaction term revealed that the male participants $(M=3.44)$ rated the wine as significantly fresher under red lighting than did the female participants $(M=3.27, P=0.046)$.

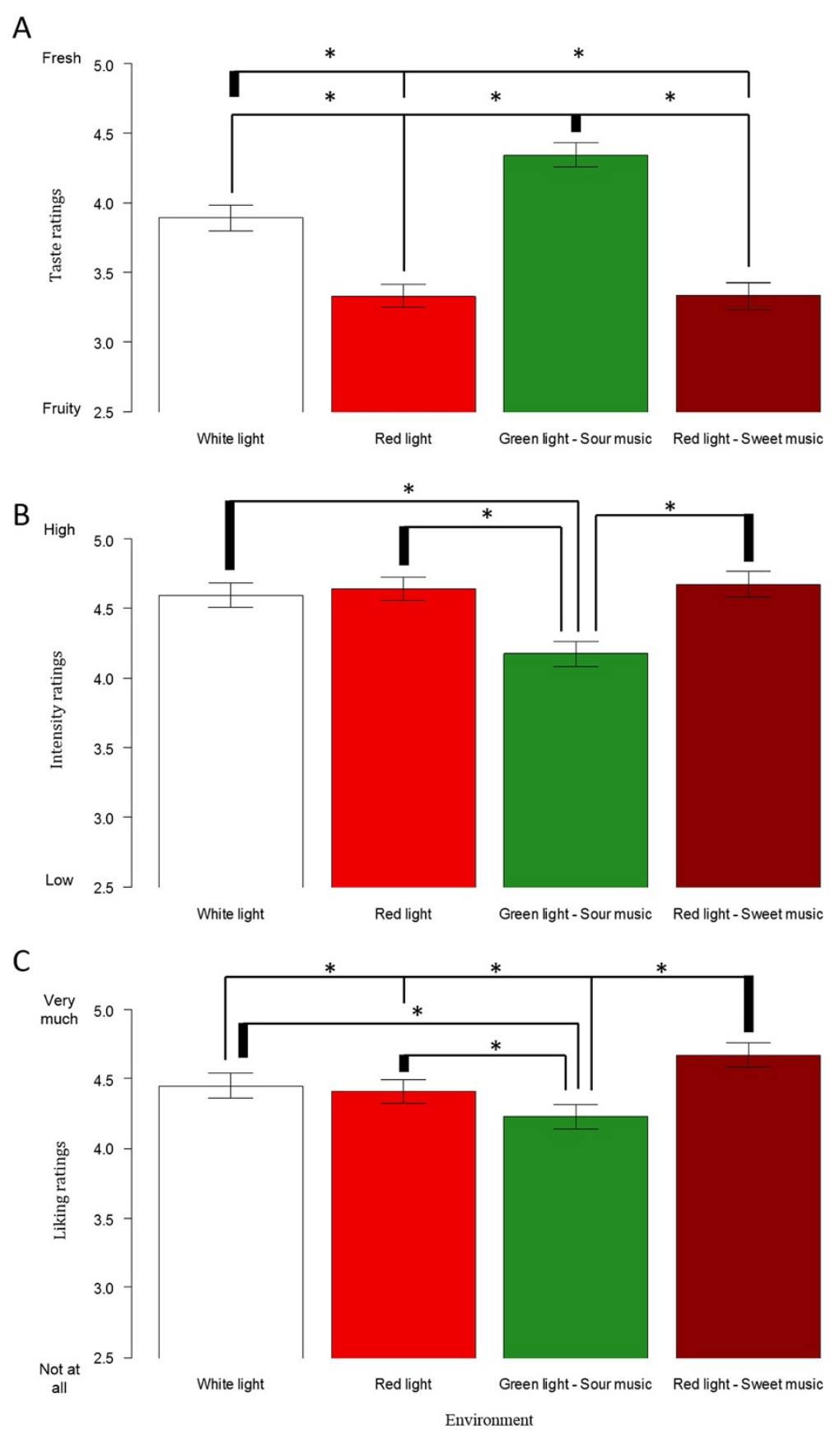

Figure 3 Mean ratings of taste (A), intensity $(\mathbf{B})$ and liking $(\mathbf{C})$ in Experiment 1. The error bars represent the standard error of the means. The thicker line shows the environment being compared and the asterisks mark those comparisons that differed significantly $(P<0.05)$. 


\section{Flavour intensity}

There were significant main effects of the environment, $F(2.970,4309.665)=31.342, P<0.001, \eta_{\text {partial }}^{2}=$ 0.021 (Figure $3 \mathrm{~B}$ ) and gender, $F(1,1451)=4.448, P=0.035$, $\eta^{2}$ partial $=0.003$, on participants' flavour intensity ratings. Pairwise comparisons revealed that the wine was rated as tasting significantly less intense in the green lighting/sour music environment than any of the other environments $(P$ $<0.001$, for all comparisons). In addition, the female participants $(M=4.58)$ tended to rate the wine as more intense than did the male participants $(M=4.47, P=0.035)$.

\section{Liking}

Analysis of participants' liking ratings (Figure 3C) revealed significant main effects of environment, $F(2.938$, $4251.669)=29.114, P<0.001, \eta^{2}$ partial $=0.005$, and gender, $F(1,1447)=12.225, P<0.001, \eta^{2}$ partial $=0.008$. According to the results of pairwise comparisons, the wine was liked more under red lighting combined with sweet music than any of the other environments $(P<0.001)$. Furthermore, the participants also liked the wine significantly more under red lighting and white lighting than under green lighting combined with sour music $(P<0.001)$. Pairwise comparisons revealed that the male participants liked the wine significantly more than did the female participants $(M=4.55$ vs. 4.33 , respectively, $P<0.001)$.

\section{Discussion}

The results of Experiment 1 clearly demonstrate that the sensory attributes of the environment in which people taste a wine can indeed exert a significant influence over their ratings (and hence also presumably on their perception) of red wine (though see [38]). While tastes undoubtedly differ $[36,39]$, the general finding to emerge from this first study is that the majority of the random sample of participants (primarily social drinkers) preferred the red wine (a Rioja) under red lighting while listening to sweet music than in any of the other three environmental conditions. That said, the addition of the sweet music only had an effect on liking ratings. (We return to a fuller discussion of this point in the General Discussion.)

Perhaps the key result to emerge from the analysis of the data from Experiment 1 is that of the more than 1,500 people who tried the red wine under the four atmospheric conditions, the general preference for the wine was when tasted under red ambient lighting while listening to the putatively sweet music. It is, however, important to bear in mind here that the participants in Experiment 1 experienced the four atmospheres in the same order (white lighting, red lighting, green lighting with sour music, and finally, red lighting with sweet music). Hence, the possibility cannot be ruled out that there might be some sort of order effects lurking in the data. Consequently, in order to address this particular concern we changed the order in which the colour/light environments were presented in Experiment 2 (conducted on the second 2 days of The Colour Lab).

\section{Experiment 2}

Methods and materials

A total of 1,309 participants (719 women, 570 men and 20 who failed to specify) aged 18 to 84 years $(M=35.4$, $S D=11.9$ ) took part in Experiment 2. Once again, $8 \%$ of the questionnaire ratings were not completed and as a consequence were excluded from the analysis. The design of Experiment 2 was identical to that of Experiment 1 with the sole exception that the four environments in which the participants rated the wine were as follows: white lighting, green lighting, red lighting with sweet music, and, finally, green lighting with sour music. The analyses were performed exactly as set out in Experiment 1.

\section{Results}

Taste (fresh vs. fruity)

Once again, there was a significant main effect of the environment on participants' ratings, $F(2.891,3569.892)=$ 26.386, $P<0.001, \eta_{\text {partial }}^{2}=0.021$ (Figure 4A). Pairwise comparisons revealed that the participants rated the wine as fresher when evaluated under green light/sour music, as compared to the other environments $(P<0.001)$, and as fresher under white light as compared to red light and sweet music $(P<0.001)$. These results are consistent with those of Experiment 1.

\section{Flavour intensity}

There were significant main effects of environment $\left(F(2.951,3685.723)=32.829, P<0.001, \eta_{\text {partial }}^{2}=0.026\right)$ (Figure $4 \mathrm{~B})$ and gender $(F(1,1249)=6.435, P=0.011$, $\eta^{2}$ partial $\left.=0.005\right)$. Pairwise comparisons revealed that the wine was rated as tasting significantly more intense under white lighting and red lighting with sweet music, as compared to green lighting alone and when paired with the sour music $(P<0.001$, for all comparisons). The participants also rated the wine as more intense under green lighting as compared to green lighting and sour music $(P=0.011)$. Additionally, the female participants rated the wine as tasting more intense overall than did the male participants $(M=4.60$ vs. 4.46 , respectively; $P=0.011$ ). The patterns of results for intensity are numerically very similar to those reported in Experiment 1 (compare Figures 3B and 4B).

\section{Liking}

Analysis of the participants' liking ratings revealed significant main effects of environment $(F(2.933,3672.711)=$ 49.204, $P=0.001, \eta^{2}$ partial $=0.038$ ) (Figure 4C) and gender $\left(F(1,1252)=10.664, P=0.001, \eta_{\text {partial }}^{2}=0.008\right)$, as well as a significant interaction term $(F(2.933,3672.711)=3.883$, 


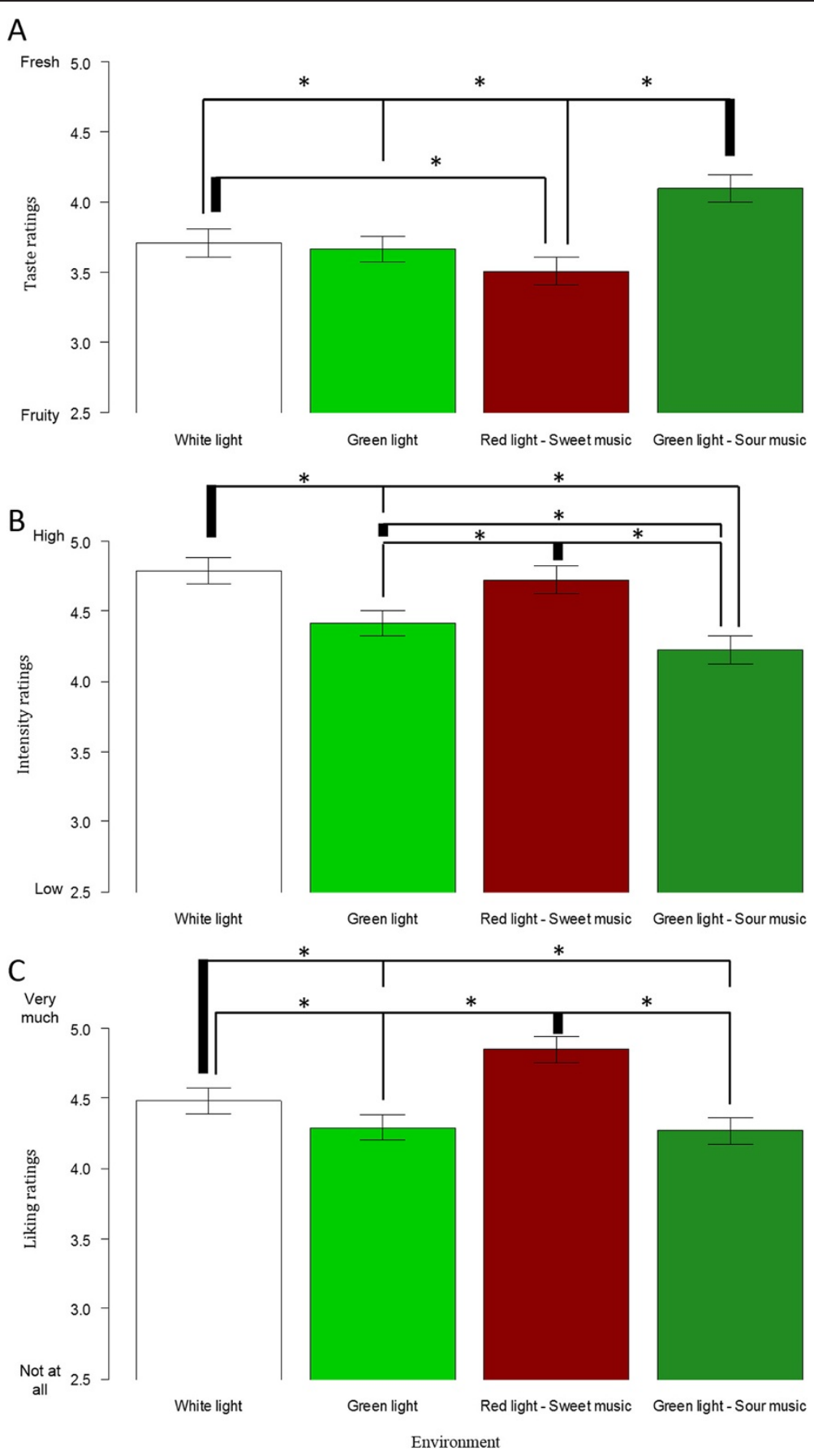

Figure 4 Mean ratings of taste (A), intensity $(B)$ and liking $(C)$ in Experiment 2. The error bars represent the standard error of the means. The thicker line shows the environment being compared and the asterisks mark those comparisons that differed significantly $(P<0.05)$.

$\left.P=0.009, \eta_{\text {partial }}^{2}=0.003\right)$. Pairwise comparisons revealed that the wine was liked significantly more when rated in the red lighting/sweet music environment, as compared to any of the other environment (all $P_{\mathrm{s}}<0.001$ ). The participants also liked the wine more under white light than under green lighting no matter whether the sour music was playing $(P<0.001)$. Pairwise comparisons revealed a significant gender difference with the male participants once again tending to like the wine more than the female participants $(M=4.57$ vs. 4.36 , respectively; $P=0.001)$. Post-hoc analysis of the gender by environment interaction revealed that men liked the wine more than did the women in under white light $(P<0.001)$, red light $(P=$ $0.005)$ and green light/sour music $(P=0.023)$. 
Overall, the results of Experiment 2 replicate the findings of Experiment 1 in showing that, on average, the participants liked the wine significantly more under red lighting when paired with sweet music than in any of the other three environmental conditions.

\section{General discussion}

The results of the two experiments reported here provide empirical support for Oberfeld et al. [11] claim that the colour of the environment can influence people's (social drinkers in both studies) wine tasting experience. In particular, our results demonstrate that the red wine (a Campo Viejo Reserva 2008) was perceived as significantly fresher and less intense under green lighting, as compared to either red or white lighting. In both of the experiments reported here, the red lighting tended to bring out the fruitiness (as compared to the freshness) of the red wine. Perhaps most importantly, the participants liked the wine most under the red lighting while listening to the sweet music in both experiments. Taken together, these results demonstrate that the environment in which a wine is tasted can indeed exert a significant influence on the perception of wine (at least as indicated by the ratings of a random sample of social drinkers) ${ }^{\mathrm{e}}$.

To give an idea of the magnitude of the change in ratings that were attributable to the change of environment, the results reported here reveal a maximum increase of 0.6 points in a 7 -point liking scale (or a $9 \%$ change) when immersed in red lighting, with 'sweet' sounding music playing. People found the wine noticeably fresher and less intense when tasted under green lighting with 'sour' music playing in the background. The increase in freshness equated to a 1-point (or 14\%) change, and the decrease in intensity 0.6 points (a $9 \%$ drop), respectively, on the 7 -point rating scales.

\section{Explaining the impact of the environment on the wine drinking experience}

Having demonstrated that the visual, and to a lesser extent the auditory, attributes of the environment can affect the rating of wine by a random sample of social drinkers, the question then arises as to what the mechanism mediating these effects might be. One possibility here is that changes in ambient lighting, and/or changes in the background sounds can elicit a change in salivation. Any such change might, in turn, be expected to affect the taste of the wine [40]. However, such an overt orienting account [41] would seem unlikely given that one of the only studies to have directly assessed the impact of environmental lighting and sound on salivatory flow [42] failed to document any significant effect of changing the lighting from bluish-white to red, or presenting the sound of wailing sirens, kitchen noises and conversation, or silence on salivatory flow rates ${ }^{f}$.
Another potential mediator of the cross-modal effect of the atmosphere on the wine tasting experience might be the meaning and any associations conveyed by different lighting colours (or types of music). In many contexts, the colour red signals negative valence, danger/loss, and has been linked to avoidance behaviour in humans [43]. Green, by contrast, has been associated with positive valence, gains and approach behaviour. According to such an account, it might seem surprising that red lighting led to the highest liking ratings for the wine sampled in the present study (see also $[44,45]$, for suppressive effects of red on consumption/usage).

It would, however, seem reasonable to assume that environmental colour may be interpreted differently depending on the particular situational context (for example, [46]): While red and green may generally serve as cues for negative and positive valence, respectively, contextspecific colour associations are likely to supersede such general associations in food consumption settings [47]. Specifically, during food consumption, individuals may draw upon red and green colours as indicators of likely taste and flavour based on learned associations between food colours and specific tastes. So, for example, redness in fruit typically signals ripeness and a sweet taste, whereas a green colour typically indicates unripe and/or sour (and possibly bitter) fruits and vegetables [4,16-19,21]. Red is obviously also a very successful colour in the soft drinks aisle (think of Coca-Cola red). Such cross-modal correspondences between basic tastes and flavours on the one hand, and colours, sounds, shapes and so on on the other have become a rapidly growing area of interest for many researchers and marketers $[19,48-50]^{\mathrm{g}}$.

As for the background music, it is worth mentioning that that sharpness and roughness are inversely related to sensory pleasantness [51]. Hence, it is worth noting that the 'sour' music is likely to have been perceived as less pleasant than the 'sweet' music, at least based on the predictions of psychoacoustic models of pleasantness. As such, one could imagine a kind of 'sensation transference' effect [52-55] from people's feelings about the music (that is, like vs. dislike, or like less) carrying over to influence their ratings of how much they liked the wine. Importantly, such as account is based on the basic response to the music rather than necessarily any fit between the music and the lighting. It should also be noted that the 'sour' music used in the present study was higher in pitch than the 'sweet' music. Previous research has suggested that higher pitched sounds tend to be perceived as colder, drier and harder than sounds having a lower pitch [56,57]. These associations may have been reflected in the different ratings of the wine. For example, the fresh/fruity ratings may have been influenced by the higher pitched notes of the sweet music. Future 
research may aim to disentangle the effects of the different attributes of a soundscape (that is, pitch, tempo, identity) in the wine-drinking experience [37].

With this kind of research, where the participants were obviously aware of what was being manipulated, namely the music and the lighting, one should always consider the extent to which people actually perceived the wine to change its perceptual qualities on the one hand, versus just changing the judgments that they made about the experience on the other [38]. One bit of evidence speaking in favour of the former interpretation was the many infor$\mathrm{mal} /$ anecdotal comments from members of the public who had been through the experience of The Colour Lab (Table 1). One thing that was very noticeable subjectively was how rapidly the taste/flavour of the wine seemed to change following a change of the ambient lighting colour. That said, it should be remembered that the participants tasted from one and the same black wine glass throughout the experiment. If anything, this is likely to have evoked a unity assumption (namely a belief in the participants that the taste of the drink was unlikely to change [58]). Should the present experiment be repeated with different glasses being handed out in each environment it is very well possible that an even bigger effect of the atmosphere on people's wine ratings may be obtained. And following on from the intriguing work of Litt and Shiv [38], one could also think that it might be interesting to repeat the present experiment after participants had been exposed to tastechanging substances like miraculin.

One important caveat when it comes to interpreting the results of the present study is that we cannot say anything about how long-lasting the effects of environmental changes on the wine tasting experience are. Note that the participants were exposed to all four environments over a period of no more than 7 to 8 minutes. Follow-up studies would therefore be needed before anything concrete could be concluded about the long-term effects of the environment on the experience of wine (or any other food or drink product for that matter).

Further research is also needed to fully address the question of how much of the effect of adding the music changed in the presence versus absence of the congruent lighting. There are now a growing number of studies showing that what we hear can exert a significant impact on what we taste $[22,27,59]$. Interestingly, the results of five out of the six ratings in the presented study showed significant differences as a function of whether or not the congruent music was presented. Such results are clearly inconsistent with a straight sensory (i.e., visual) dominance account as outlined earlier. However, it is difficult to say whether the auditory and visual environmental cues combined in an additive $v s$. in a superadditive manner without conducting further research. In particular, one would need to compare a music-only versus a music-
Table 185 participants responded to the questions "What did you think of Campo Viejo's Colour Lab? Has it changed your taste perceptions?" and are presented here

Did you like the experiment/experience? Tell us about
your experience

1 A very interesting experience of taste and flavours. The lighting was like going through the 4 seasons and gave the wine a very different taste.

2 Absolutely. I now see why they make wine red.

3 Absolutely. Very surprised by changes.

$4 \quad$ Amazing experience (and I don't drink alcohol). Still don't like wine, But loved to taste and feel the difference as a scientific sensorial experience. And great to find I'm a supertaster. Great host by the way!

$5 \quad$ Amazing. Very interesting. Would love to know results!

$6 \quad$ Brilliant experience. Loved it!!

$7 \quad$ Brilliant! Was a bit sceptical but it works!

$8 \quad$ Brilliant!! Definitely changed my perceptions. Who would have guessed?

9 Brilliant, extremely interesting \& something I had never considered.

10 Cool experience. Let's me understand more how your environment can affect your taste buds.

11 Definitely. Fascinating experience.

12 Enjoyed it - Has definitely changed my perceptions on taste.

13 Excellent, enlightening experience, something to think about.

$14 \quad$ Fantastic experience. Really interesting. Changed perceptions completely.

15 Fascinating! Flavour/colour connection: The change was instant. How curious!

16 Good fun... Interesting to see how colour and sound changes taste and perception

17 Great \& new ideas about taste experience relationship.

18 Great experience \& really interesting. I am a chef - So always curious about new taste experience. Keep me posted.

19 Great experience. I didn't think the colour/sound would alter my perception as much as that!

20 Great fun! Love red lights. Brought out flavour of berries.

21 Great idea \& lovely staff.

22 I think this is something creative and different and totally changed my taste perceptions.

23 I thought it was brilliant \& really showed me the influence of environment to taste as well as difference in each person's own taste.

$24 \quad$ I was mildly aware of sound and light changes but this has confirmed it.

25 I'm amazed. I thought for me drinking it was mood dependent. But now I think environment plays a big part too!

26 Incredibly interesting. I couldn't have expected such a different change of taste.

27 Interesting science behind how taste can be influenced. Thank you. 
Table 185 participants responded to the questions "What did you think of Campo Viejo's Colour Lab? Has it changed your taste perceptions?" and are presented here (Continued)

\begin{tabular}{|c|c|}
\hline 28 & $\begin{array}{l}\text { Interesting to see how colour effects your taste buds. Red } \\
\text { is my favourite. }\end{array}$ \\
\hline 29 & $\begin{array}{l}\text { It was a fun experience. I have never tried wines like this } \\
\text { before. }\end{array}$ \\
\hline 30 & It was a great and unexpected experience. \\
\hline 31 & It was fantastic, Thank you. \\
\hline 32 & Love the event. Love the wine anyways. \\
\hline 33 & $\begin{array}{l}\text { Loved it. Great experience. Can't believe how much taste } \\
\text { changed. }\end{array}$ \\
\hline 34 & Loved it. Yes - An "eye opener". \\
\hline 35 & Marvellous. \\
\hline 36 & $\begin{array}{l}\text { Never realised how much colour and music could alter my } \\
\text { perception of wine. }\end{array}$ \\
\hline 37 & OMG. Can't believe it is same wine. \\
\hline 38 & $\begin{array}{l}\text { One of the funniest ways I've ever had to taste a wine! } \\
\text { Well done Campo Viejo! }\end{array}$ \\
\hline 39 & $\begin{array}{l}\text { Proved colour and sound does and can change your } \\
\text { perception. }\end{array}$ \\
\hline 40 & Quite bizarre! Such different flavours! \\
\hline 41 & $\begin{array}{l}\text { Quite interesting. Thinking of changing my living room } \\
\text { lights and taste of music. }\end{array}$ \\
\hline 42 & $\begin{array}{l}\text { Really a new experience. Between the } 5 \text { trials the flavour } \\
\text { was completely different. }\end{array}$ \\
\hline 43 & Really fun \& interesting look forward to the results. \\
\hline 44 & Really fun! Always loved this wine. \\
\hline 45 & Really interesting experiment, love. \\
\hline 46 & Really interesting. Defiantly change perception. \\
\hline 47 & $\begin{array}{l}\text { Really interesting. Maybe look at the shape of the glass } \\
\text { influencing. generally super interesting }\end{array}$ \\
\hline 48 & $\begin{array}{l}\text { Really made me think about the link between senses \& } \\
\text { perception. }\end{array}$ \\
\hline 49 & Refreshing experience and good for r\&d. \\
\hline 50 & Though provoking. Surprising. \\
\hline 51 & $\begin{array}{l}\text { Totally changed seeing how different environment } \\
\text { changes the taste. Really good! }\end{array}$ \\
\hline 52 & $\begin{array}{l}\text { V. interesting, totally surprised by the influence of the } \\
\text { surrounding colour. }\end{array}$ \\
\hline 53 & Very cool, worth it! Yes very much so. \\
\hline 54 & $\begin{array}{l}\text { Very cool. Interesting! So many crushed grapes. Very, very } \\
\text { cool :) }\end{array}$ \\
\hline 55 & $\begin{array}{l}\text { Very enjoyable yes defiantly noticed difference with/ } \\
\text { without sound. }\end{array}$ \\
\hline 56 & $\begin{array}{l}\text { Very good and amazing how colour changes taste. Would } \\
\text { really love to hear results. }\end{array}$ \\
\hline 57 & $\begin{array}{l}\text { Very interesting - colour certainly did change flavour for } \\
\text { me. }\end{array}$ \\
\hline 58 & $\begin{array}{l}\text { Very interesting - next time I drink wine I shall pay more } \\
\text { attention to my surroundings. }\end{array}$ \\
\hline 59 & and unique experience. \\
\hline
\end{tabular}

Table 185 participants responded to the questions “What did you think of Campo Viejo's Colour Lab? Has it changed your taste perceptions?" and are presented here (Continued)

\begin{tabular}{|c|c|}
\hline 60 & Very interesting. Definitely changed my perception. \\
\hline 61 & $\begin{array}{l}\text { Very interesting. The taste definitely changed with the } \\
\text { colour. }\end{array}$ \\
\hline 62 & Very interesting. Need to always be in a red room. \\
\hline 63 & $\begin{array}{l}\text { Very interesting. Yes it has made me more aware of how } \\
\text { environment affects taste. }\end{array}$ \\
\hline 64 & $\begin{array}{l}\text { Very surprised at the degree of difference colour change } \\
\text { made. Less so w/sound. Thank you. V interesting. }\end{array}$ \\
\hline 65 & Was very surprised at how I was affected by the colour. \\
\hline 66 & Wow. Good stuff. Really enjoyed that one. \\
\hline 67 & $\begin{array}{l}\text { Yes - I knew it was the same wine yet colour changed my } \\
\text { opinion on how much I liked it. }\end{array}$ \\
\hline 68 & $\begin{array}{l}\text { Yes - interesting to learn about taste buds and the wine } \\
\text { was yummy. }\end{array}$ \\
\hline 69 & $\begin{array}{l}\text { Yes definitely. Don't know how but very good } \\
\text { experiments. Good luck with results. So many crushed } \\
\text { grapes. }\end{array}$ \\
\hline 70 & $\begin{array}{l}\text { Yes indeed. Fascinating stuff. Will paint all my rooms red } \\
\text { now! }\end{array}$ \\
\hline 71 & $\begin{array}{l}\text { Yes very good. May introduce colour at my next dinner } \\
\text { party. }\end{array}$ \\
\hline 72 & Yes! Interesting. Will use info in future dinner parties. \\
\hline 73 & Yes, amazing experience. \\
\hline 74 & Yes, great idea. Interested to know study results. \\
\hline 75 & Yes, I didn't expect to taste much difference but I did. \\
\hline 76 & $\begin{array}{l}\text { Yes, I didn't know just the atmosphere colour could } \\
\text { change the "taste" of a wine. }\end{array}$ \\
\hline 77 & Yes, I didn't realise how visual taste was. \\
\hline 78 & Yes, I liked the wine more with the music!! \\
\hline 79 & $\begin{array}{l}\text { Yes, it changed my taste perception. Interesting lab!! In all } \\
\text { colours change the perception - taste. }\end{array}$ \\
\hline 80 & Yes, it is interesting how colours influence our perception. \\
\hline 81 & $\begin{array}{l}\text { Yes, it was a completely different wine with the different } \\
\text { colours. }\end{array}$ \\
\hline 82 & Yes, loved it! \\
\hline 83 & $\begin{array}{l}\text { Yes, very good experience. Amazing how the same drink } \\
\text { tastes so different. }\end{array}$ \\
\hline 84 & Yes. Fascinating. \\
\hline 85 & Yes. I'm getting different lights in my home. \\
\hline
\end{tabular}

plus-lighting condition in order to determine the precise nature of the interaction between auditory and visual environmental cues. Finally, it is also worth noting that using musical selections that are even more strongly associated with a particular taste than those used here might lead to an even bigger contribution of auditory environmental cues to the overall multisensory tasting experience.

Ultimately, we believe that results such as those reported in the present study will feed into those who 
are interested in the delivery of immersive multisensory tasting experiences (for example, [60]), as well perhaps as helping those thinking about the optimal design of the atmosphere for the on-premises drinks trade and elsewhere $[29,61,62]$.

\section{Conclusions}

A large sample study on the influence of the multisensory environment on the wine drinking experience is reported. The results presented demonstrate that the environment can exert a significant influence on the perception (ratings) of wine, and provide relevant information for both researchers and practitioners that are interested in multisensory experience design. In particular, the wine was perceived as fresher and less intense under green lighting and sour music and liked more under red lighting while listening to sweet music. Further research will undoubtedly be needed in order to clarify the possible mechanisms for the effects reported.

\section{Endnotes}

${ }^{a}$ Note that under such conditions, one can be sure that changing the colour of the ambient lighting does not affect the visual appearance of the drink itself (at least for transparent drinks like wine), since the drink looks jet black within the tasting glass. Hence, any effect that remains under such conditions can undoubtedly be attributed to the change in the ambient lighting.

b Oberfeld et al. [11] argued that this may have been a result of the difference between the participants that they tested in the two studies.

${ }^{\mathrm{c}} \mathrm{We}$ assessed any difference between female and male participants on the ratings of the tasting strip in Experiments 1 and 2 by means of a paired-samples t-test. Overall, the women rated the tasting strip as significantly more bitter $(M=5.99, S D=3.8)$ than did the men $(M=5.55, S D=3.7), t(2719)=-3.025, P=0.003$. Note that this kind of sex difference has frequently been reported in the literature (for example, [63]).

${ }^{\mathrm{d}}$ Note that we did not have any clear predictions about the influence of gender, if any, on participants' responses. However, given that we had such a large dataset, and given that there are well-documented gender differences in taster status (for example, [63]), we thought it worthwhile to add this factor to the analysis.

${ }^{\mathrm{e}}$ In other words, if you do not like the wine that you happen to be drinking, you might try changing the environment, be it the colour of the lighting or the music playing in the background.

${ }^{\mathrm{f}}$ It is, however, perhaps worth noting that only 12 participants were tested, and hence further research with a much larger sample is probably needed before unequivocally ruling out a salivatory contribution to the influence of lighting and sound on taste perception.
${ }^{g}$ One might speculate as to whether the congruency between the red lighting and the assumed, if not seen, redness of the wine in the glass may have played any role in driving up the participants' liking ratings. Specifically, the cognitive processing of the putatively red wine combined with the red lighting may have been, in some sense, more fluent [64].

\section{Competing interests}

Funding for this study came from Campo Viejo and Pernod Ricard.

\section{Authors' contributions}

CS developed the idea of the research project. CS contributed to the data for Experiments 1 and 2. KK and collaborators provided the auditory stimuli for use in Experiments 1 and 2. CS, CV and KK conducted the analysis and interpretation of the data, and drafted the manuscript. All authors approved the final version.

\section{Acknowledgments}

The authors would like to thank Klangerfinder GmbH for allowing us to use the sweet and sour sounds in the present study. The authors would also like to thank Campo Viejo and Pernod Ricard for generously supporting The Colour Lab. Logistical support for the event was expertly handled by Miss Jones and Co.

CS is supported by the Rethinking the Senses grant from the AHRC. Carlos Velasco would like to thank COLFUTURO, Colombia, for financial support toward his PhDs.

\section{Author details}

${ }^{1}$ Crossmodal Research Laboratory, Department of Experimental Psychology, University of Oxford, 9 South Parks Road, Oxford OX1 3UD, UK. ²Department of Marketing, BI Norwegian Business School, Nydalsveien 37, Oslo 0484, Norway.

Received: 6 June 2014 Accepted: 14 July 2014

Published: 1 October 2014

\section{References}

1. Morrot G, Brochet F, Dubourdieu D: The color of odors. Brain Lang 2001, 79:309-320.

2. Pangborn RM, Berg HW, Hansen B: The influence of color on discrimination of sweetness in dry table-wine. Am J Psychol 1963, 76:492-495.

3. Parr W, White KG, Heatherbell D: The nose knows: Influence of colour on perception of wine aroma. J Wine Res 2003, 14:79-101.

4. Spence C, Levitan C, Shankar MU, Zampini M: Does food color influence taste and flavor perception in humans? Chemosens Percept 2010, 3:68-84

5. Spence C, Piqueras-Fiszman B: The multisensory packaging of beverages. In Food packaging: Procedures, management and trends. Edited by Kontominas MG. Hauppauge, NY: Nova Publishers; 2012:187-233.

6. Spence C, Piqueras-Fiszman B: The perfect meal: The multisensory science of food and dining. Oxford: Wiley-Blackwell; 2014.

7. Wheatley J: Putting colour into marketing. Marketing 1973, 67:24-29.

8. Gal D, Wheeler SC, Shiv B: Cross-modal influences on gustatory perception. [http://ssrn.com/abstract=1030197]

9. $\mathrm{Xu} \mathrm{AJ}$, Labroo AA: Incandescent affect: Turning on the hot emotional system with bright light. J Consum Psychol 2014, 24:207-216.

10. Evans D: Emotion: The science of sentiment. Oxford: Oxford University Press; 2002.

11. Oberfeld $D$, Hecht $H$, Allendorf $U$, Wickelmaier F: Ambient lighting modifies the flavor of wine. J Sens Stud 2009, 24:797-832.

12. Sauvageot F, Struillou A: Effet d'une modification de la couleur des échantillons et de l'éclairage sur la flaveur de vins évaluée sur une échelle de similarité (Effect of the modification of wine colour and lighting conditions on the perceived flavour of wine, as measured by a similarity scale). Sci Aliment 1997, 17:45-67.

13. Ross CF, Bohlscheid J, Weller K: Influence of visual masking technique on the assessment of 2 red wines by trained and consumer assessors. J Food Sci 2009, 73:S279-S285. 
14. Gregson RAM: Modification of perceived relative intensities of acid tastes by ambient illumination changes. Aust J Psychol 1964, 16:190-199.

15. Wilson GD, Gregson RAM: Effects of illumination on perceived intensity of acid tastes. Aust J Psychol 1967, 19:69-72.

16. Hidaka S, Shimoda K: Investigation of the effects of color on judgments of sweetness using a taste adaptation method. Multisens Res, in press.

17. Koch C, Koch EC: Preconceptions of taste based on color. J Psychol ISO 2003, 137:233-242

18. Lavin JG, Lawless HT: Effects of color and odor on judgments of sweetness among children and adults. Food Qual Prefer 1998, 9:283-289.

19. Maga JA: Influence of color on taste thresholds. Chem Senses Flavor 1974 1:115-119.

20. O'Mahony M: Gustatory responses to nongustatory stimuli. Perception 1983, 12:627-633.

21. Pangborn RM: Influence of color on the discrimination of sweetness. Am J Psychol 1960, 73:229-238.

22. Crisinel A-S, Cosser S, King S, Jones R, Petrie J, Spence C: A bittersweet symphony: Systematically modulating the taste of food by changing the sonic properties of the soundtrack playing in the background. Food Qual Prefer 2012, 24:201-204.

23. Mesz B, Sigman M, Trevisan MA: A composition algorithm based on crossmodal taste-music correspondences. Front Hum Neurosci 2012, 6:1-6.

24. Mesz B, Trevisan M, Sigman M: The taste of music. Perception 2011, 40:209-219.

25. Spence C: Sound design: How understanding the brain of the consumer can enhance auditory and multisensory product/brand development. In Audio Branding Congress Proceedings 2010. Edited by Bronner K, Hirt R, Ringe C. Baden-Baden, Germany: Nomos Verlag; 2011:35-49.

26. Spence C, Richards L, Kjellin E, Huhnt A-M, Daskal V, Scheybeler A, Velasco C, Deroy O: Looking for crossmodal correspondences between classical music \& fine wine. Flavour 2013, 2:29.

27. Spence $C$, Deroy $\mathrm{O}$ : On why music changes what (we think) we taste. i-Perception 2013, 4:137-140.

28. Partan S, Marler P: Communication goes multimodal. Science 1999, 283:1272-1273.

29. Spence C, Puccinelli N, Grewal D, Roggeveen AL: Store atmospherics: A multisensory perspective. Psychol Market 2014, 31:472-488.

30. Stein BE, Meredith MA: The merging of the senses. Cambridge, MA: MIT Press; 1993.

31. Spence C: The ICl report on the secret of the senses. London: The Communication Group; 2002.

32. Rock I, Harris CS: Vision and touch. Sci Am 1967, 216:96-104.

33. Rock I, Victor J: Vision and touch: An experimentally created conflict between the two senses. Science 1964, 143:594-596.

34. Bartoshuk LM: Comparing sensory experiences across individuals: Recent psychophysical advances illuminate genetic variation in taste perception. Chem Senses 2000, 25:447-460.

35. Spence C: The supertaster who researches supertasters. [http://www.bps-researchdigest.blogspot.co.uk/2013/10/day-4-of-digest-super-week-supertaster.html]

36. Bartoshuk L: Separate worlds of taste. Psychol Today 1980, 14:48-49. 51-54-56, 63

37. Knöferle KM, Spence C: Crossmodal correspondences between sounds and tastes. Psychon Bull Rev 2012, 19:992-1006.

38. Litt A, Shiv B: Manipulating basic taste perception to explore how product information affects experience. J Consum Psychol 2012, 22:55-66.

39. Prescott J: Taste matters: Why we like the foods we do. London: Reaktion Books; 2012.

40. Spence C: Mouth-watering: The influence of environmental and cognitive factors on salivation and gustatory/flavour perception. J Texture Stud 2011, 42:157-171.

41. Spence C: Orienting attention: A crossmodal perspective. In The Oxford Handbook of Attention. Edited by Nobre AC, Kastner S. Oxford: Oxford University Press; 2014:446-471.

42. Pangborn RM, Lundgren B, Drake B, Nilsson U: Effects of light and sound on parotid secretion and taste perception in response to sodium chloride. Chem Senses Flavour 1978, 3:81-91.

43. Elliot AJ, Maier MA, Moller AC, Friedman R, Meinhardt J: Color and psychological functioning: The effect of red on performance attainment. J Exp Psychol Gen 2007, 136:154-168.

44. Bruno N, Martani M, Corsini C, Oleari C: The effect of the color red on consuming food does not depend on achromatic (Michelson) contrast and extends to rubbing cream on the skin. Appetite 2013, 71:307-313.
45. Genschow $\mathrm{O}$, Reutner L, Wanke M: The color red reduces snack food and soft drink intake. Appetite 2012, 58:699-702

46. Elliott A, Maier MA: Color psychology: Effects of perceiving color on psychological functioning in humans. Annu Rev Psychol 2014, 65:95-120.

47. Jacquier C, Giboreau A: Perception and emotions of colored atmospheres at the restaurant. In Predicting Perceptions: Proceedings of the 3rd International Conference on Appearance. Edinburgh: Lulu Press; 2012:165-167.

48. Obrist M, Comber R, Subramanian S, Piqueras-Fiszman B, Velasco C, Spence C: Taste experiences: A framework for design. CHI 2014, 2853-2862 [http://dl.acm.org/citation.cfm?id=2557007]

49. Spence C: Crossmodal correspondences: A tutorial review. Atten Percept Psychophys 2011, 73:971-995

50. Spence C: Managing sensory expectations concerning products and brands: Capitalizing on the potential of sound and shape symbolism. J Consum Psychol 2012, 22:37-54.

51. Fastl H, Zwicker E: Psychoacoustics: facts and models. Berlin: Springer; 2011.

52. Clore GL, Huntsinger JR: How emotions inform judgment and regulate thought. Trends Cogn Sci 2007, 11:393-399.

53. Lawless HT, Heymann H: Sensory evaluation of food: Principles and practices. Gaithersburg, MD: Chapman \& Hall; 1997.

54. Thorndike EL: A constant error in psychological ratings. J Appl Psychol 1920, 4:25-29.

55. Yamasaki T, Yamada K, Laukka P: Viewing the world through the prism of music: Effects of music on perceptions of the environment. Psychol Music 2013. doi:10.1177/0305735613493954/.

56. Eitan Z, Timmers R: Beethoven's last piano sonata and those who follow crocodiles: cross-domain mappings of auditory pitch in a musical context. Cognition 2011, 114:405-422.

57. Eitan Z, Rothschild I: How music touches: Musical parameters and listeners' audiotactile metaphorical mappings. Psychol Music 2010, 39:449-467.

58. Woods AT, Poliakoff E, Lloyd DM, Dijksterhuis GB, Thomas A: Flavor expectation: The effects of assuming homogeneity on drink perception. Chemosens Percept 2010, 3:174-181

59. North AC: The effect of background music on the taste of wine. Brit J Psychol 2012, 103:293-301.

60. Velasco C, Jones R, King S, Spence C: Assessing the influence of the multisensory environment on the whisky drinking experience. Flavour 2013, 2:23

61. Sester C, Deroy O, Sutan A, Galia F, Desmarchelier J-F, Valentin D, Dacremont C: "Having a drink in a bar": An immersive approach to explore the effects of context on beverage choice. Food Qual Prefer 2013, 28:23-31.

62. Bacon J: Consumers value stores' appearance and atmosphere. [http://www. marketingweek.co.uk/trends/trending-topics/shopper-behaviour/consumersvalue-stores-appearance-and-atmosphere/4010022.article on 06/06/14]

63. Bartoshuk LM, Duffy VB, Miller IJ: PTC/PROP tasting: anatomy, psychophysics, and sex effects. Physio/ Behav 1994, 56:1165-1171.

64. Labroo AA, Dhar R, Schwartz N: Of frog wines and frowning watches: Semantic priming, perceptual fluency, and brand evaluation. $J$ Consum Res 2008, 34:819-831.

doi:10.1186/2044-7248-3-8

Cite this article as: Spence et al.: A large sample study on the influence of the multisensory environment on the wine drinking experience. Flavour 2014 3:8.

\section{Submit your next manuscript to BioMed Central and take full advantage of:}

- Convenient online submission

- Thorough peer review

- No space constraints or color figure charges

- Immediate publication on acceptance

- Inclusion in PubMed, CAS, Scopus and Google Scholar

- Research which is freely available for redistribution 